\title{
The prevalence of Infectious Bronchitis (IB) in some chicken farms in Egypt: III. Cross protection of vaccinated chickens versus field IB virus
}

\author{
K. M. Kamel ${ }^{1}$, A. A. Bassiouni ${ }^{2}$, M. A. Afify ${ }^{2}$, N.S. Rabie ${ }^{2}$ \\ ${ }^{I}$ Department of Poultry Diseases, National Research Center, Cairo and ${ }^{2}$ Department of Poultry \\ Diseases, Faculty of Veterinary Medicine, Cairo University.
}

\begin{abstract}
Four groups of one-day-old SPF chicks were inoculated with the four IBV variants at 1 day old to study the virulence of these isolates. The results at 2 weeks post infection (PI) revealed that all isolates were able to induce serological resposne postinfection, respiratory distress and depression. $20 \%$ and $100 \%$ mortalities were recorded with isolates 4 and 23; respectively. Assessment of pathogenicity index and pathotyping (at the end of observation period " $2 \mathrm{wk}-\mathrm{PI}$ "), categorized the 4 tested isoaltes $(4,16,18,23)$ into three isoaltes of high virulence $(4,18$ and 23$)$, and one isolate of intermediate virulence (16). About $50 \%$ reduction in body weight was recorded with the four IBV isolates 2 wk PI. Kidney lesions were nephritis-nephrosis with urate deposition in ureters, while microscopic lesions were associated with increase in the amount of rough endoplasmic reticulum (RER). Tracheal lesions recorded as increase the amount of mucin, while microscopic lesions were edema of mucosa and inflammatory cells in the lamina propria. The regime of administering the infectious bronchitis (IB) live commercial $H_{120}$ vaccine at 1 day old SPF chicks, and the heterologous challenge with four variants (serotypes) at 4 weeks of age, was found to be poorly effective in protecting the respiratory tract of SPF chickens with protection percentages of $8.1 \%$, $55 \%, 10.5 \%$ and $12.6 \%$ corresponding to field isolates of IBV $4,16,18$ and 23 ; respectively. Protection was measured by assessing ciliary activity of the tracheal epithelium following challenge. It is suggested that the use of the live $I B-H_{120}$ vaccine will not always broaden the protection against challenge with IB multiple serotypes isolated from Egypt. Therefore it is necessary to develop a new IB vaccines, either locally prepared or imported to overcome any new IB serotype that were emerged, through modifying vaccination strategies to make them appropriate to the field situation.
\end{abstract}

For an effective vaccination program, the isolation and identification of IBV isolates are important because vaccines are selected on the basis of the serotypes present in specific geographic areas (Yu et al., 2001).

In Egypt, IB was first described by Ahmed, (1954), subsequently several reports(Eissa et al., 1963; Ahmed, 1964; Amin and Moustageer, 1977; Sheble et al., 1986; Bastami et al., 1987; Mousa et al., 1988; El-Kady, 1989; Mahmoud, 1993; Ahmed, 2002; Abdel Moneim et al., 2002; Madbouly et al., 2002; Sultan et al., 2004; Lebdah et al., 2004; Sediek, 2005) emphasized the prevalence of the disease. Massachusetts (Mass) type live attenuated vaccine (H120) as well as inactivated oil emulsion vaccine are applied to prevent and control the incidence of the disease.

Our previous papers, we isolated 4 varient strains of IBVs from field outbreaks and well identified with RT-PCR and sequenced int Europian lab.

The aim of this study was to investigate the prevalence of IBVs in Egypt and their evolutionary relationship to the present work particularly interested to know whether the recently isolated Egyptian IBV strains which escaped from vaccine- elicited immunity were newly introduced in the chicken population or arose by mutations of circulating Egyptian IBV strains .This is important for implementation of control measures especially for the future vaccination strategies.

\section{Viruses of IB.}

\section{Materials and methods}

Infectious Bronchitis disease vaccine (live virus). Commercial live H120 vaccine, IB Vaccine Nobilis, strain H-120 (Massachusetts), 1000 dose, batch number: $90016 \mathrm{G}$, was used. This vaccine employed in cross protection 
experiment supplied by local agency of, Intervet International B.V., Boxmeer-Holland.

Challenge IB virus. The viruses used in the challenge were in form of infectious allantoic fluid at the level of fifth -passage, they were isolated from field cases confermed by RT-PCR and characterized by sequencing as variant IBV strains. They were titrated in SPF embryonated eggs as described by Villegas and Purchase, (1990), with titer $\left(10^{6.0-6.6}\right)$ and its calculation according to (Reed and Muench, 1938).

Experimental chickens. Sufficient one-day-old chicks were hatched from SPF fertile chicken eggs obtained from (Nile SPF), incubated and hatched, floor reared under strict hygienic condition in isolated experimental rooms, previously cleaned and disinfected. Chicks were provided with commercial broiler ration, water and feed were provided adlibidum. They used for pathogenicity test and cross protection study.

Solution for scanning electron microscope (SEM). Preparation of tracheal rings for scanning electron microscope (SEM) (Dutta, 1975).

Scoring indexes for clinical, lesions and pathogenicity. They were recorded according to (Avellaneda et al., 1994; Wang and Huang, 2000).

ELISA Serum Samples: were separated and checked by ELISA for detection of specific IBV antibodies using commercial ELISA (ELISAsynbiotic).

Histopathology. Histopathology was routinely conducted according to (Bancroft and Steven, 1977).

Cross protection test. To evaluate the protection of the respiratory tract provided by live-attenuated IB vaccine against challenge with IBV isolates that proved to be variant by sequencing. Seventy one day old specific pathogens free (SPF) chicks were used in this test. Pre-experiment, 10 chicks were sacrified, serologically tested (ELISA-synbiotic) to assure freedom of specific IB-antibody. The remaining 60 chicks were divided into two groups (A and B) 30 chicks each. 30 chicks in group (A) were adminstred live $\mathrm{H} 120$ vaccine at one day of age by oculonasal route at the manufacture's recommended bird dose. 30 chicks in group (B) were left as non vaccinated. Both groups were housed under strict hygienic measures in separate experimental rooms. They were provided with food and water ad libitum, daily observed for 4 weeks.

At 4 weeks of age, 10 chicks from group (A) and group B were bled, serologically tested for detection of specific IBV antibodies. Chicks of group A were subdivided to 5 subgroups, 6 chicks of each coded subgroup $A_{1}$ to subgroup $A_{5}$. Each subgroups from $A_{1}$ to $A_{4}$, was inoculated via the oculo-nasal route with $10^{6.4}$, $10^{6.3}, 10^{6.6}$ and $10^{6.0}$ embryo infective dose $\left(\mathrm{EID}_{50}\right)$ (previous titrated in embryonated eggs) in a volume of $100 \mu \mathrm{l}$ per chick of one of the four typed IBV-field isolate coded 4, 16, 18 and 23; respectively. Additional subgroup A5, was left as vaccinated non challenged group.

Chicks in group $\mathrm{B}$, were subdivided to 5 subgroups, 6- chicks of each, coded subgroup $B_{1}$ to subgroup $B_{5}$. Subgroups from $B_{1}$ to $B_{4}$, were similarly inoculated with one of the four typed IBV isolates. An additional, subgroup $\mathrm{B}_{5}$ was left as non vaccinated non challenged group. Each subgroup was housed in separate experimental rooms, with an observation period of 5 days. At day 5 pi, the chicks were sacrified by cutting the Jugular vein (in inverted way to avoid contaminating the trachea with blood). Tracheas were washed thoroughly in glass Petridish containing approximately $5 \mathrm{ml}$ of Hanks balanced solt solution (HBSS). This washing step to remove mucin content in trachea lumen. Tracheas were cut into 1.5 -to- $2.0 \mathrm{~mm}$ width using sterile razor blade into rings in the HBSS. Each trachea was cut into 10 rings (3-upper, 4medium and 3 lower). Rings were placed in-10well tissue culture macroplate (one ring per well, and one plate per trachea). Examination performed for ciliary activity under inverted microscope $(4 \mathrm{x}$ or $10 \mathrm{x}$ objective) processed, further for scanning electron microscopy (SEM).

\section{Results}

The pathogenicity of the four IBV isolated variants by sequencing test. Seventy one-day old SPF chicks were used for evaluation of the pathogenicity of IBV isolates (coded 4, 16, 18 and 23) and divided as in (Table 1).

ELISA revealed freedom of the tested 10 one day old chicks' sera from specific antibodies against IBV (preinfection).

Evidence of seroconversion. Sera collected at 14 days pi belonged to 3 IBV field isolates coded $4,16,18,23$ and vaccine strain $(\mathrm{H} 120)$ are summarised in (Table 2). Evidence of seroconversion are $75 \%, 90 \%, 80 \%$, and $100 \%$ in chicks infected with IBV 4, 16, 18, and H120; respectively. Isolate 23 not tested, where all infected chicks were dead on day 5 and 6 PI (not survived at 14 days PI). 
Pathogenicity test analysis. For each group, the scores were pooled and the final scores were the average of the pooled scores. All infected chicks in groups 2, 3, 4 and 5 representating groups infected with IBV isolates 4, 16, 18 and 23; respectively (Table 3), signs of head and depression at 24 and 48 hours after virus inoculation were obtained. Sick chicks showed varying degrees of coughing, sneezing, tracheal rales, watery feces and watery eyes (Figs 1- 4). Recorded clinical scores were 2.25, 1.6 and 1.8 for isolates 4, 16 and 18; respectively. Score of isolate 23 was not recorded, where all chicks were dead on day 5 and 6 pi (Table 3).Obtained mortalities were $20 \%, 0.0 \%, 0.0 \%$ and $100 \%$ with isolates 4, 16, 18 and 23; respectively (Table 3 and 4). Pathogenicity index were 22, 18, 19 and 30 for isolates 4, 16, 18 and 23; respectively based on the necropsy of kidney and trachea of the survivor and dead chicks. So, isolates can be classifed according to the pathogenicity index to highly, intermediat, highly and higly pathogenic for isolates code 4 , 16, 18 and 23; respectively (Table 4)(Figs 5-11). The main common lesions were swollen and pale kidneys together with tubules and ureters distincted by urate (Fig 12 and 13) (Table 5).

Effect of IBV on body weight. As shown in Table (6), IBV affected the performance of the infected chicks as judged by the body weight gain in groups infected with isolates 4,16 , and 18 where $49.9,45.47$ and 48.5 reductions in body weight percentage were obtained; respectively.

Microscopic kidney lesions. Principally, kidney lesions of IBV-infected chicks were of an interstitial nephritis. The virus caused granular degeneration, vaculation and desquamation of the tubular epithelium, and massive infilteration of hetrophils in the interstitium. The lesions in tubules was most prminent in the medulla. Inflammatory cell population, lymphocytes and plasma cells were seen (Table 7) and Figs (1418).

Microscopic tracheal lesions. The common findings in trachea of chicks infected at 1 day old with field isolates of IBVs were generally localized in the mucosa and lamina propria. The mucosa revealed variable degrees ranged from edema to mild or sever pronounced degeneration of the epithelial lining. Sometimes, goblet cells were activated and coalesce forming wide vacules (Figs 19 and 20).

The lamina propria revealed mild congested blood vesseles associated with hemorrhages, and infiltration with inflammatory cells. Concerning chicks infected with H120 live vaccine, pronounced activation of goblet cells was characterized (Table 8 and Figs 21-24).

Results of reisolation. IBV could be isolated from organs collected from both dead and survived birds of groups 2, 3, 4 and 5 representing groups inoculated with IBV isolates $4,16,18$ and 23; respectively.

The possibility of the protection provided by live attenuated IB vaccine against challenge with field IBV isolates. To evaluate the protection of the respiratory tract provided by live attenuated IB-vaccine against challenge with field IBV isolates.

Seventy, one day old SPF chicks were used, 10 chicks were sacrified for serological examination by ELISA then the remainng birds were divided as shown in (Table 9).

Table (1): Experimental design of pathogenicity testing in one day old chicks.

\begin{tabular}{cclc}
\hline \multirow{2}{*}{ Group } & \multirow{2}{*}{ No. of chicks } & \multicolumn{2}{c}{ Treated group/ Isolate No. } \\
\cline { 3 - 4 } & 10 & * Slaughtered, serology testing & Inoculation dose (EID50 /ml) \\
\hline 1 & 10 & Inoculated with isolate Code (4) & $10^{6.4}$ \\
2 & 10 & Inoculated with isolate Code (16) & $10^{6.3}$ \\
3 & 10 & Inoculated with isolate Code (18) & $10^{6.6}$ \\
4 & 10 & Inoculated with isolate Code (23) & $10^{6.0}$ \\
5 & 10 & Inoculated with live IBV vaccine (H120) & Field dose \\
6 & 10 & Negative control (PBS infected) & \\
7 & &
\end{tabular}

*Ten serum samples were checked by ELISA at one day old (pre-experiment) to assure freedom from specific IBV antibodies. 
Table (2): Serological response of SPF chicks infected at 1 day old with IBVs and examined at 14 days age as Judged by ELISA (Synbiotic).

\begin{tabular}{|c|c|c|c|c|c|c|c|c|c|c|}
\hline \multirow{2}{*}{\multicolumn{2}{|c|}{ IBV strain }} & \multirow[t]{2}{*}{ Exam. No. } & \multicolumn{6}{|c|}{ Descriptive Statistics } & \multirow[t]{2}{*}{ Post No. } & \multirow[t]{2}{*}{ Post \% } \\
\hline & & & Min. & Max & Mean & GMT & SD & $\% \mathrm{CV}$ & & \\
\hline \multicolumn{2}{|l|}{4} & 8 & 0 & 1426 & 610 & 143 & 487 & 56.183 & 6 & 75 \\
\hline \multicolumn{2}{|l|}{16} & 10 & 0 & 1506 & 697 & 340 & 490 & 45.23 & 9 & 90 \\
\hline \multicolumn{2}{|l|}{18} & 10 & 0 & 1348 & 550 & 161 & 460 & 51.47 & 8 & 80 \\
\hline \multicolumn{2}{|l|}{23} & 0 & 0 & NT & NT & NT & NT & NT & NT & NT \\
\hline \multicolumn{2}{|l|}{$\mathrm{H}_{120}$} & 10 & 189 & 2020 & 746 & 568 & 589 & 48.543 & 10 & 100 \\
\hline \multicolumn{2}{|c|}{ Control } & 10 & 0 & 0 & 0 & 0 & 0 & 166.25 & 0 & 0 \\
\hline \multirow{4}{*}{$\begin{array}{l}\text { Exam } \\
\% \\
\text { Max } \\
\text { NT }\end{array}$} & $=$ & Examined & & $\mathrm{T}$ & \multirow{3}{*}{\multicolumn{2}{|c|}{$\begin{array}{l}\text { Geometric } r \\
\text { Minimum } \\
\text { Standard de }\end{array}$}} & an titer & No & $=$ & Number \\
\hline & $=$ & Percentage & & $=$ & & & & $\mathrm{CV}=$ & \multicolumn{2}{|c|}{ Coefficience of variance } \\
\hline & $=$ & Maximum & & $=$ & & & ation & Post. & $=$ & Positive \\
\hline & $=$ & Not tested & where & fecte & hicks d & $\mathrm{d}$ on $\mathrm{da}$ & 5,6 pi) & & & \\
\hline * Posi & $\mathrm{e}=$ & Based on $\mathrm{I}$ & SA ti & aual & r over & 5 cons & r positi & & & \\
\hline
\end{tabular}

Table (3): Clinical scoring of SPF chicks infected at 1 day old with IBVs and slaughtered at 14 day pi.

\begin{tabular}{cccccc}
\hline Group & $\begin{array}{c}\text { IBVs } \\
\text { (isolates code) }\end{array}$ & \multicolumn{2}{c}{ Observation within 14 days post infection } & \multicolumn{2}{c}{ Clinical } \\
\cline { 3 - 5 } & Infected No. & Survived No. & Dead No. & NT \\
\hline 1 & Slaughtered (a) & 10 & 0 & 0 & 2.25 \\
2 & 4 & 10 & 8 & 0 & 1.6 \\
3 & 16 & 10 & 10 & 0 & 1.8 \\
4 & 18 & 10 & 10 & $10(\mathrm{~b})$ & NC \\
5 & 23 & 10 & 10 & 0 & 0 \\
6 & $\mathrm{H}_{120}$ Vacc & 10 & 10 & 0 & 0 \\
7 & Control & & 0 & 0 & 0 \\
\hline
\end{tabular}

(a) slaughtered at one day old for serological testing and proved negative by ELISA

(b) 5 chicks dead on day 5, and 5 chicks dead on day 6 post-infection.

Control $=$ non infected $\quad \mathrm{NT}=$ not tested (slaughtered pre-experiment).

$\mathrm{NC}=$ not calculated, where chick were dead at 5 and 6 days pi.

Clinical score (Avellaneda et al., 1994; Wang and Huang, 2000) =

Score $0=$ No clinical signs;

Score 1 = lacrimation, slight shaking of head, watery feces;

Score 2 = lacrimation, presence of nasal exudate, depression, watery feces;

Score 3 = strong (lacrimation, presence of nasal exudate, depression, severe watery feces).

Table (4): Pathogenicity index results based on necropsy of kidney and trachea of SPF chicks infected at 1 day old with IBVs and examined (survivors and dead) during 14 days observation.

\begin{tabular}{|c|c|c|c|c|c|c|c|c|}
\hline \multirow{2}{*}{$\begin{array}{c}\text { IBV } \\
\text { Isolate } \\
\text { code }\end{array}$} & \multirow{2}{*}{$\begin{array}{c}\text { No. } \\
\text { infected }\end{array}$} & \multicolumn{3}{|c|}{ Observation record } & \multicolumn{2}{|c|}{ Score } & \multirow{2}{*}{$\begin{array}{l}\text { Pathogenicity } \\
\text { index (a) }\end{array}$} & \multirow[t]{2}{*}{ Pathotype(b) } \\
\hline & & Dead & Survive & Mortality\% & Kidney & Trachea & & \\
\hline 4 & 10 & 2 & 8 & 20 & 10 & 10 & 22 & High \\
\hline 16 & 10 & 0 & 10 & 0 & 8 & 10 & 18 & Intermediate \\
\hline 18 & 10 & 0 & 10 & 0 & 10 & 9 & 19 & High \\
\hline 23 & 10 & 10 & 0 & 100 & 10 & 10 & 30 & High \\
\hline $\mathrm{H}_{120}$-vacc. & 10 & 0 & 10 & 0 & 0 & 2 & 2 & Low \\
\hline Control & 10 & 0 & 10 & 0 & 0 & 0 & 0 & - \\
\hline
\end{tabular}

Vacc. $=$ Vaccine

Kidney and trachea score $=$ No of chicks with lesion score of $\geq 1$

(a) pathogenicity index $=$ No of chicks with lesion score $\geq 1+1$ point for every $10 \%$ mortality.

(b) pathotype = low (pathogenicity index value 1-9), intermediate (pathogenicity index vlaue 10-18),

High (pathogenicity index value $\geq 19$ ) 
Table (5): Results of necropsy of SPF chicks infected at one day old with IBVs and examined survivor and dead during 14 days observation.

\begin{tabular}{|c|c|c|c|c|c|c|c|c|c|c|c|c|c|c|}
\hline \multirow[b]{3}{*}{$\begin{array}{c}\text { IBV } \\
\text { Isolate } \\
\text { code }\end{array}$} & \multicolumn{14}{|c|}{ Necropsy record } \\
\hline & \multicolumn{5}{|c|}{ Air Sacs } & \multicolumn{4}{|c|}{ Trachea } & \multicolumn{3}{|c|}{ Kidney } & \multirow[b]{2}{*}{ 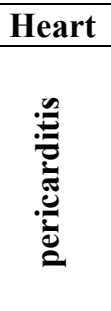 } & \multirow[b]{2}{*}{ 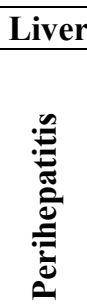 } \\
\hline & 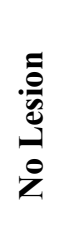 & 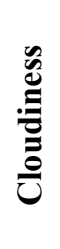 & 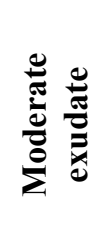 & 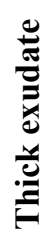 & 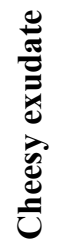 & 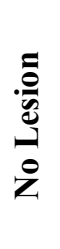 & 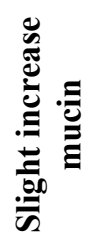 & 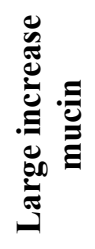 & 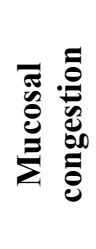 & 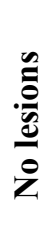 & 包 & & & \\
\hline 4 & 0 & 10 & 4 & 5 & 1 & 0 & 3 & 5 & 3 & 0 & 10 & 2 & 2 & 0 \\
\hline 16 & 0 & 10 & 3 & 7 & 0 & 0 & 1 & 1 & 8 & 2 & 8 & 1 & 0 & 0 \\
\hline 18 & 0 & 9 & 3 & 4 & 2 & 1 & 9 & 0 & 9 & 0 & 10 & 2 & 0 & 0 \\
\hline 23 & 0 & 10 & 3 & 2 & 0 & 0 & 3 & 7 & 3 & 0 & 10 & 10 & 0 & 0 \\
\hline $\mathrm{H}_{120}$ & 8 & 2 & 0 & 0 & 0 & 8 & 2 & 0 & 0 & 10 & 0 & 0 & 0 & 0 \\
\hline Control & 10 & 0 & 0 & 0 & 0 & 10 & 0 & 0 & 0 & 10 & 0 & 0 & 0 & 0 \\
\hline
\end{tabular}

Table (6): Effect of IBVs on body weight of survivor SPF chicks infected at one day old and recorded at 14 day old.

\begin{tabular}{lccccc}
\hline Item & \multicolumn{4}{c}{ IBV-isolated infected groups } \\
\cline { 2 - 6 } & $\mathbf{4}$ & $\mathbf{1 6}$ & $\mathbf{1 8}$ & $\mathbf{H}_{\mathbf{1 2 0}}$ & Control \\
\hline Survivor No. & 8 & 10 & 10 & 10 & 10 \\
Range & $90.66-130.44$ & $99.57-133.71$ & $86.81-135.53$ & $200.2-218$ & $202-218$ \\
Mean & 105.71 & 115.57 & 108.74 & 210 & 210.9 \\
BW\% & 50.1 & 54.56 & 51.5 & 99.5 & $100 \%$ \\
Reduction in BW\% & 49.9 & 45.47 & 48.5 & 0.5 & 0 \\
\hline
\end{tabular}

$\mathrm{BW} \%=\frac{\text { Mean body weight of infected birds }}{\text { Mean body weight of non infected birds }} \times 100$

Reduction in BW \% $=$ BW\% of non infected group - BW\% of infected group. Chicks infected with IBV (isolate 23) not recorded (where all chicks dead on day 5 and 6 post infection).

Table (7): Results of Histopathological lesions in kidneys associated with infection of one day old SPF chicks with IBVs and examined (survivors) at 14 days pi.

\begin{tabular}{lcccccc}
\hline IBVs Isolate code & Oedema & Degeneration & Necrosis & Inflammatory cells & Urates & RER \\
\hline Isolate No. 14 & ++ & +++ & ++ & ++ & - & ++ \\
Isolate No. 16 & + & + & + & ++ & - & + \\
Isolate No. 18 & + & + & + & + & + & + \\
$\mathrm{H}_{120}$ (Vacc.) & + & + & + & - & + \\
\hline
\end{tabular}

Vacc. $=$ Vaccine $\quad$ Oedema $=$ swelling of infected epithelial cells. Degeneration $=$ granular degeneration of tubular epithelium. Necrosis = focal area of necrosis in tubular epithelium. Inflammatory cells = tubular epithelium, mostly in medulla infilterated with inflammatory cells (Hetrophils, Lymphocytes and plasma cells). Urates $=$ ureters distended with urates and sometimes with casts. RER = increase the amount of rough endoplasmic reticulm (RER).

Table (8): Results of histopathological lesions in trachea associated with infection of 1 day old SPF chicks with IBVs and examined (survivors) at 14 days pi.

\begin{tabular}{|c|c|c|c|c|c|c|c|}
\hline \multirow[b]{2}{*}{$\begin{array}{l}\text { IBVs } \\
\text { Isolates } \\
\text { code }\end{array}$} & \multicolumn{4}{|c|}{ Mucosa } & \multicolumn{3}{|c|}{ Lamina propria } \\
\hline & Oedema & $\begin{array}{c}\text { Epithelial } \\
\text { cell } \\
\text { degeneration }\end{array}$ & $\begin{array}{c}\text { Goblet } \\
\text { cell } \\
\text { activated }\end{array}$ & $\begin{array}{c}\text { Goblet } \\
\text { cell } \\
\text { coalesce }\end{array}$ & $\begin{array}{c}\text { Congested } \\
\text { blood } \\
\text { vesseles }\end{array}$ & Hemorrhages & $\begin{array}{c}\text { Inflammatory } \\
\text { cells }\end{array}$ \\
\hline Isolate (4) & ++ & + & - & - & + & + & + \\
\hline Isolate (16) & + & +++ & + & + & +++ & +++ & + \\
\hline Isolate (18) & + & ++ & - & - & + & ++ & + \\
\hline $\mathrm{H}_{120}$ (vacc.) & - & - & + & - & - & - & - \\
\hline Control & - & - & - & - & - & - & - \\
\hline
\end{tabular}



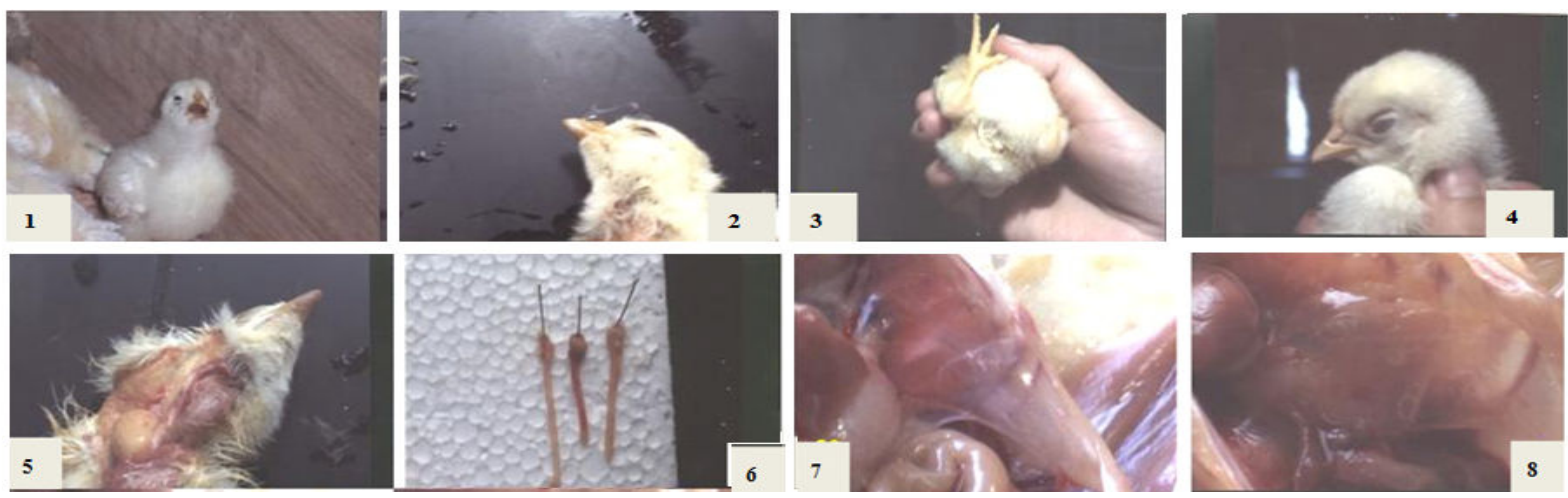

A.Clinical signs developed in experimental pathogenicity testing.

Fig. (1): Severe gasping of SPF chick developed within 2 days after infection with field isolate of IBV.

Fig. (2): Frothy nasal exudates and nasal discharge.

Fig. (3): Watery feces as Judged by soiled vent feather.

Fig. (4): Wet eye.

B. Gross lesions developed in experimental pathogenicity testing.

Fig. (5): Congested trachea after infection developed in experimental chicks.

Fig. (6): Trachea revealed different degrees of congestion.

Fig. (7): Thoracic air sac showing turbidity and cloudness.

Fig. (8): Frothy thoracic air sac developed in dead SPF chick after infection with field isolate of IBV.
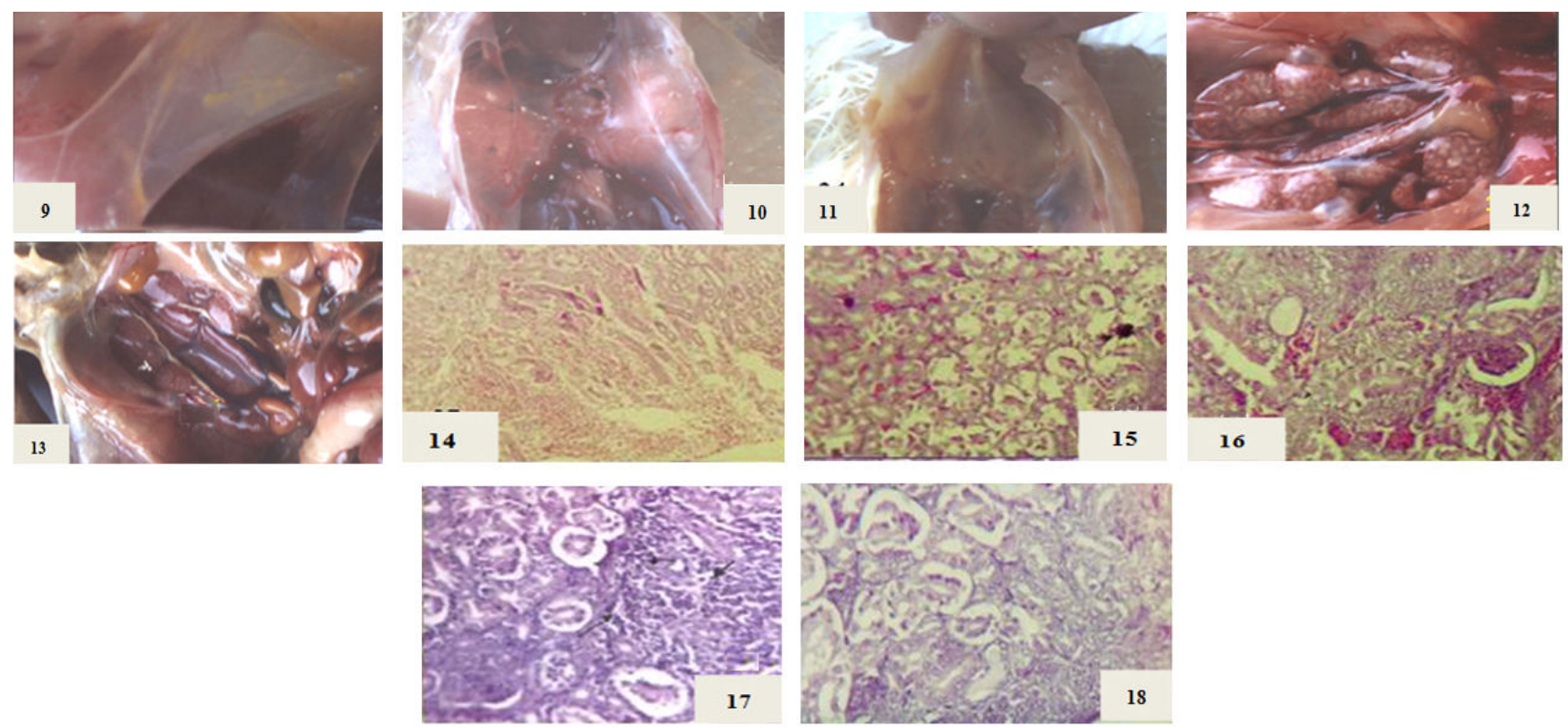

Fig. (9):Cloudy and yellowish thoracic air sac developed in dead SPF chick after infection with field isolate of IBV.

Fig. (10): Lung with focal area of pneumonia and turbid thoracic air sac.

Fig. (11): Pericarditis and yellowish exudates in thoracic air sac.

Fig. (12): Pale kidney with nephritis and deposition of uric acid in ureters of survived SPF chick after 14 days of infection with field isolate of IBV.

Fig. (13): Deposition of uric acid in ureters of survived SPF chick after 14 days of infection with field isolate of IBV.

Histopathological findings of kidney of infected 1 day old SPF chicks with IBV (No.16 \& 18) and examined (survivor) at 14 days pi.

Fig. (14): Severe congestion and hemorrhages within tubular epithelium, mostly in medulla in chicks infected with IBV (No.16) (H \&E. x 100).

Fig. (15): Severe degenerative changes of renal tubules in chicks infected with IBV (No.16) (H \& E. x 100). Fig. (16): Marked degenerative and undifferentiated renal tubules in chicks infected with IBV (No.18) (H \&E. $x$ 100).

Fig. (17): Aggregation of inflammatory cells (hetrophils, lymphocytes and plasma cells) in tubular epithelium, mostly in medulla in chicks infected with IBV (No.18) (H \& E. x 250). 

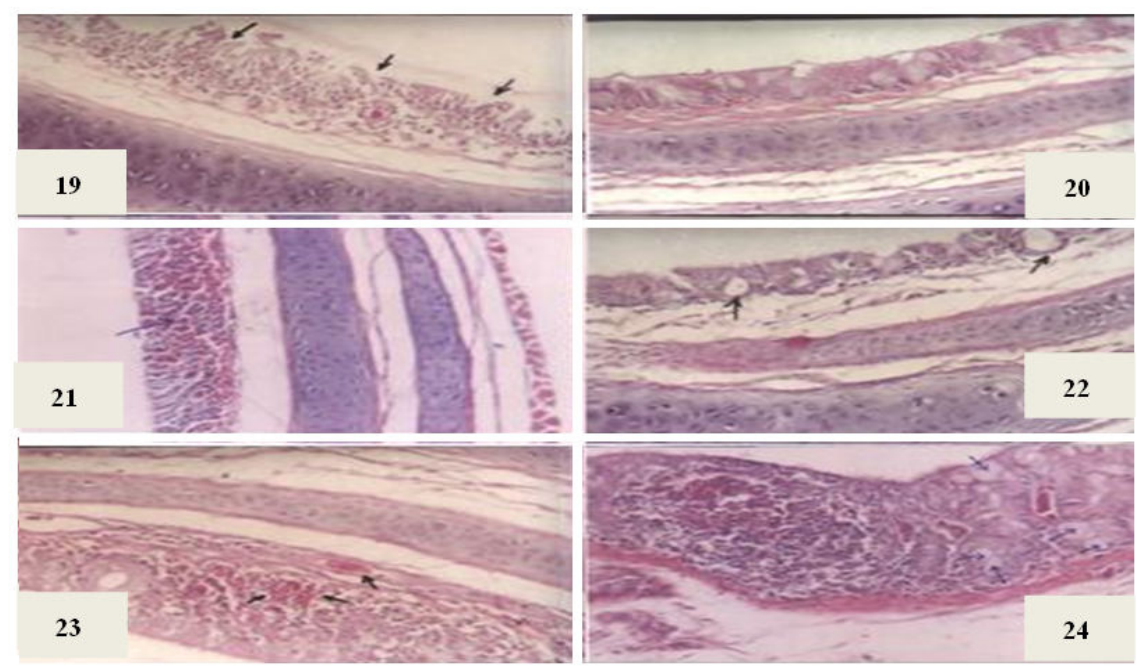

Histopathological findings of trachea of infected 1 day old SPF chicks with IBV (18,16 and H 120) and examined (survivor) at 14 days pi.

Fig. (19): Mucosa of trachea infected with IBV (18) showed degenerative changes in epithelial lining cells (H \& $E$. $x$ 250).

Fig. (20): Mucosa of trachea infected with IBV (No.16) revealed degeneration of epithelial lining and activation of goblet cells (H \& E. x 250).

Fig. (21): Lamina propria of trachea infected with IBV (No.16) have severe hemorrhages (H \& E. x 250).

Fig. (22): Activated goblet cells of trachea infected with IBV (No.16) (H \& E. x 250).

Fig. (23): Hemorrahges in lamina propria of trachea infected with IBV (No.18) (H \& E. x 250).

Fig. (24): Activated goblet cells of trachea vaccinated with H120 (H \& E. x 250).

A

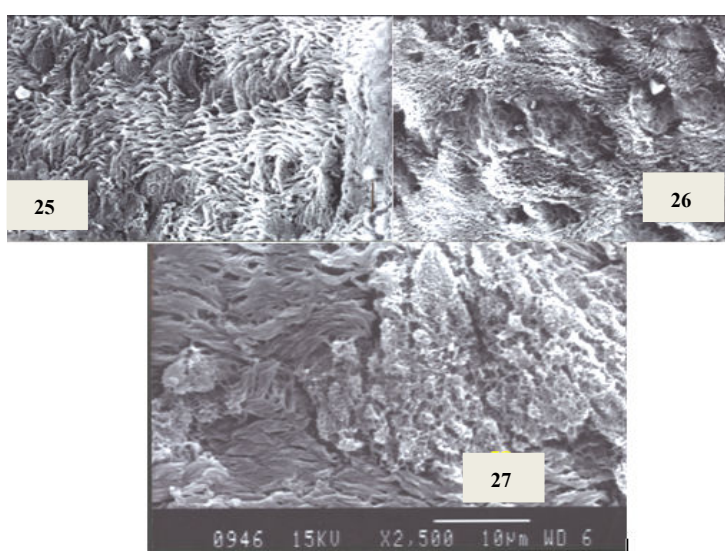

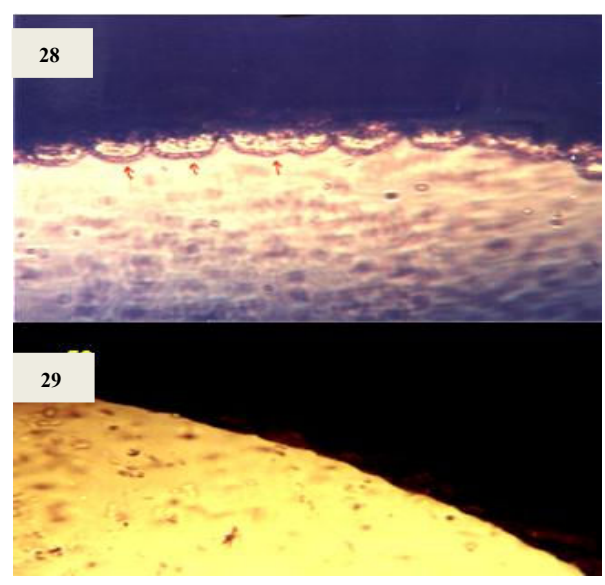

A. Electron microscopy scanning (EMS) for trachea

Fig. (25): Trachea of control chicks.Complete ciliary activity.

Fig. (26): Trachea of non vaccinated-challenged chicks. Complete ciliostasis.

Fig. (27): Trachea of vaccinated-challenged chicks. Complete ciliary activity (left) and complete ciliostasis (right).

$B$. Breadth of protection of respiratory tract provided by live attenuated IB vaccine $(H$ 120) against challenge with IBV of heterologous serotype.

Fig. (28): Complete presence of tracheal cilia in non-infected SPF chicks as demonstrated with inverted microscope.

Fig. (29): Ciliostasis with complete detachment of tracheal cilia of SPF chick, 4-days post-challenge with IBV (isolate 16) as demonstrated with inverted microscope.

Results in which various heterologous IBV strains were used for challenge of 4 weeks old SPF chickens vaccinated at one day old by $\mathrm{H} 120$ vaccine are summarized in Table (10). Clinical signs percentages (in vaccinated challenged groups) were 100, 50, 100 and 100, for IBV isolates 4, 16, 18 and 23; respectively (Table, 10). $33.3 \%$ mortality was observed in non vaccinated group challenged with isolate code 23
(Table 10). H120 vaccine protected poorly against challenge with IBV isolates 4, 16, 18 and 23 where protection percentage were 8.1, 55, 10.5 and 12.6; respectively (Table 11). Complete ciliary activity of trachea either by EM scanning or inverted microscope examination is presented (Figs 25 and 28) and complete ciliostasis (Figs 26 and 29) and partial ciliostasis (Fig 27). Serology results are shown in (Table 12). 
Table(9): Experimental design (for cross protection study).

\begin{tabular}{|c|c|c|c|c|c|}
\hline \multirow[t]{2}{*}{ Group } & \multirow[t]{2}{*}{ Subgroup } & \multirow{2}{*}{$\begin{array}{l}\text { No. of } \\
\text { birds }\end{array}$} & \multicolumn{2}{|c|}{ Treated groups/ isolate No } & \\
\hline & & & 1day old & 4weeks old & \\
\hline \multirow{5}{*}{ A } & Subgroup A1 & 6 & $\mathrm{H}_{120}$ Vac. & Isolate 4 & \\
\hline & Subgroup A2 & 6 & $\mathrm{H}_{120}$ Vac. & Isolate 16 & Vaccinated \\
\hline & Subgroup A3 & 6 & $\mathrm{H}_{120}$ Vac. & Isolate 18 & Challenge \\
\hline & Subgroup A4 & 6 & $\mathrm{H}_{120}$ Vac. & Isolate 23 & Groups \\
\hline & Subgroup A5 & 6 & $\mathrm{H}_{120}$ Vac. & PBS & Vaccinated non challenge control \\
\hline \multirow{5}{*}{ B } & Subgroup B1 & 6 & & Isolate 4 & \\
\hline & Subgroup B2 & 6 & & Isolate 16 & $\begin{array}{l}\text { Non Vaccinated } \\
\text { Challenge }\end{array}$ \\
\hline & Subgroup B3 & 6 & & Isolate 18 & Challenge \\
\hline & Subgroup B4 & 6 & & Isolate 23 & \\
\hline & Subgroup B5 & 6 & & Sterile PBS & Non vaccinated non challenge control \\
\hline
\end{tabular}

Table (10): Development of clinical signs and mortalities during 5 days postchallenge with IBVs at 4 weeks of age in SPF chicks (vaccinated and non vaccinated at 1 day old with live $\mathrm{H}_{120}$ vaccine).

\begin{tabular}{|c|c|c|c|c|c|c|c|c|c|c|}
\hline \multirow{3}{*}{$\begin{array}{l}\text { Item } \\
\text { Subgroup }\end{array}$} & \multicolumn{10}{|c|}{ Group } \\
\hline & \multicolumn{4}{|c|}{ A (Vacc/chall) } & \multicolumn{4}{|c|}{ B (Non vacc/chall) } & \multicolumn{2}{|c|}{ C (Control groups) } \\
\hline & A1 & A2 & A3 & A4 & B1 & B2 & B3 & B4 & A5 & B5 \\
\hline Number & 6 & 6 & 6 & 6 & 6 & 6 & 6 & 6 & 6 & 6 \\
\hline IBV-challenge strain & 4 & 16 & 18 & 23 & 4 & 16 & 18 & 23 & & \\
\hline Signs: d1-pc & 0 & 0 & 1 & 0 & 0 & 0 & 0 & 1 & 0 & 0 \\
\hline d2-pc & 0 & 0 & 2 & 3 & 6 & 2 & 2 & 5 & 0 & 0 \\
\hline d3-pc & 2 & 1 & 6 & 6 & 6 & 6 & 6 & 6 & 0 & 0 \\
\hline d4-pc & 6 & 3 & 6 & 6 & 6 & 6 & 6 & $5(a)$ & 0 & 0 \\
\hline d5-pc & 6 & 3 & 6 & 6 & 6 & 6 & 6 & $4(\mathrm{~b})$ & 0 & 0 \\
\hline Deaths-No. & 0 & 0 & 0 & 0 & 0 & 0 & 0 & 2 & 0 & 0 \\
\hline Sign \% & 100 & 50 & 100 & 100 & 100 & 100 & 100 & 100 & 0 & 0 \\
\hline Mortality\% & 0 & 0 & 0 & 0 & 0 & 0 & 0 & 33.3 & 0 & 0 \\
\hline
\end{tabular}

$\mathrm{d}=$ day, $\mathrm{pc}=$ post-challenge, vacc $=$ vaccinate, chall $=$ challenge,

A5 $=$ vaccinated non challenge. $\quad$ B5 $=$ Non vaccinated non challenge

clinical signs $=$ include one or more signs of depression, lacrimation, slight shake head, swollen head, soft dropping, respiratory signs.

(a) One chick was died in $\mathrm{d} 4 \mathrm{PC}$ (remaining 5 chicks)

(b) One chick was died in d5PC (remaining 4 chicks)

Table (11): Results of cross protection test as judged by tracheal ciliary activity.

\begin{tabular}{|c|c|c|c|c|c|c|c|c|}
\hline \multirow{3}{*}{ Item } & \multicolumn{4}{|c|}{ Group A (vaccinate/challenge) } & \multirow{2}{*}{\multicolumn{4}{|c|}{$\begin{array}{c}\text { Group B (non vaccinate/challenge) } \\
\text { Sub-group B }\end{array}$}} \\
\hline & \multicolumn{4}{|c|}{ Sub-group A } & & & & \\
\hline & A1 & $\mathbf{A 2}$ & $\mathbf{A 3}$ & A4 & B1 & B2 & B3 & B4 \\
\hline Vace. & $\mathrm{H}_{120}$ & $\mathrm{H}_{120}$ & $\mathrm{H}_{120}$ & $\mathrm{H}_{120}$ & - & - & - & - \\
\hline IBV-C & 4 & 16 & 18 & 23 & 4 & 16 & 18 & 23 \\
\hline No. Exam. & 6 & 6 & 6 & 6 & 6 & 6 & 6 & 4 (a) \\
\hline (b) Mean ciliostasis score & 36.3 & 16.65 & 33.8 & 34.3 & 39.5 & 37.0 & 37.8 & 39.3 \\
\hline Protection\% & 8.1 & 55 & 10.5 & 12.6 & & & & \\
\hline
\end{tabular}

IBV. Chall $=$ IBV challenge strain. Vacc $=$ Vaccination

Group $A=$ vaccinated at 1 day old with IBV-vaccine (H120), challenged at 28 day old.

Group $B=$ Non vaccinated, challenged at 28 day old.

IBV-challenge strain: isolate 4 (A1, B1), isolate 16 (A2, B2), isolated 18 (A3, B3), isolate 23 (A4, B4)

(a) Two chick found dead (not examined)

protection score $\%=\left[1-\frac{\text { mean ciliostasis score for vacc-chall-group }}{\text { mean ciliostasis score for non-vacc-chall-group }}\right] \times 100$ 
Table (12): IB antibody titre of chicks at 1 day old (pre-experiment) and 28 days (pre-challenge from groups A and B) as judged by ELISA (synbiotic).

\begin{tabular}{|c|c|c|c|c|c|c|c|c|c|c|c|}
\hline \multirow[t]{2}{*}{ Group } & \multirow{2}{*}{$\begin{array}{c}\text { No. of } \\
\text { samples }\end{array}$} & \multirow[t]{2}{*}{ Age/day } & \multirow[t]{2}{*}{ Treatment } & \multicolumn{6}{|c|}{ Descriptive statistics } & \multirow{2}{*}{$\begin{array}{l}\text { Post } \\
\text { No. }\end{array}$} & \multirow{2}{*}{$\begin{array}{c}\text { Post } \\
\%\end{array}$} \\
\hline & & & & Min & Max & Mean & GMT & SD & $\% \mathrm{CV}$ & & \\
\hline Pre-experiment & 10 & 1 & No treatment & 0 & 0 & 0 & 0 & 0 & 81.04 & 0 & 0 \\
\hline Group A & 10 & 28 & $\begin{array}{c}\text { Vacc } \mathrm{H}_{120} \text { at } 1 \\
\text { day old }\end{array}$ & 1412 & 3804 & 2395 & 2249 & 878 & 22.73 & 10 & 100 \\
\hline Group B & 10 & 28 & $\begin{array}{c}\text { vaccinated at } 1 \\
\text { day old }\end{array}$ & 0 & 0 & 0 & 0 & 0 & 34.85 & 0 & 0 \\
\hline
\end{tabular}

$\begin{array}{lll}\begin{array}{l}\text { No }=\text { Number } \\ \text { Max }=\text { Maximum }\end{array} & \begin{array}{l}\text { Min }=\text { Percentage } \\ \text { post }=\text { Positive }\end{array} & \text { CV }=\text { Coefficience of variance } \\ \text { GMT }=\text { Geometric mean titre }\end{array}$

$\mathrm{SD}=$ Standard deviation. $\quad$ Positive $=$ Based of ELISA titer equal to or over 165 considered positive.

\section{Discussion}

In the present study four IBV isolates which were characterized as variants, were examined further to evaluate their pathogenicity, day old SPF chicks were selected because we expected them to be most susceptible to infection at this age and they were also free of antibodies titer against IBV as well as free from other infectious agents (Dhinkar and Jones, 1996). Three IBV isolates $(4,16$ and 18$)$ were capable to induce respiratory signs pi with clinical score of 2.25 , 1.6 and 1.8; respectively. Also, respiratory lesions (air sacs and trachea) and renal (kidney) lesions were obtained. These findings agreed with Ignjatovic and Sapats, (2000), who reported that strains of IBV differ in virulence or pathogenicity for the respiratory tract, kidney or oviduct. Although the virulence of many IBV strains had not been clearly defined, examples illustrated the predominant feature of each pathotype. The majority of IBV strains, including those of the Massachusetts (Mass) serotype, of which the M41 is the representative strain, produce prominent respiratory disease as recorded by Cavanagh and Naqi, (1997). Most of these strains do not induce mortality when acting alone. However, in experimental infections, variable mortality rates are obtained, indicating the differing pathogenic potential of strains to predispose chicks to the development of airsaculitis, pericarditis and perihepatitis as similler to Smith et al., ( 1985).

Concerning the capability of IBV field isolates to induce mortality pi, only two IBV isolates (4 and 23) were able to produce $20 \%$ and $100 \%$ death; respectively. The high mortality rate observed in one day old chick that experimantally inoculated with isolate code 23 compared to mortality pattern in the original flock (layer-41week old) can be explained by the fact that the most sever clinical response of IBV appear in very young chicks and as age increases chickens become more resistant to IBV induced mortality (Smith et al., 1985). These findings accord with Wang et al., (1996), who reported that IBV alone in experimental infection could cause death after infection ranged from 10, 20, 50 and 60 percent in experimental infected chicken groups.

It was well documented that IB had a significant economic impact in broilers whereas production losses may due to poor weight gains (Ignjatovic and Sapats, 2000). Our results found, where severe losses in broiler weights on a comparison of control group as a sequence of infection with IBV field variant isolates coded 4, 16 and 18 reached $49.9 \%, 45 \%$ and $48.5 \%$; respectively. This may be explained as the affected chicks suffered from depression and marked reduction in the feed consumption which result in significant loss of body weight from 3 days after infection (Otsuki et al., 1990).

Some IBV strains either caused nephrosisnephritis in young birds or else contributed to urolethiasis in layers (Cowen et al., 1987).Three of our IBV isolates were nephropathogenic strains, where they induced gross renal urate deposition and histological lesions in the experimental chicks. Similarly, variants of IB were reported as nephropathic, M41, 720/99 Israil, D274, D3896, D311, D3896, D1559, D3128, 4/91 (Bastami et al., 1987; Eid, 1998; Abdel-Moneim et al., 2002; Madbouly et al., 2002; Lebdah et al., 2004; Sultan et al., 2004; Sediek, 2005). Nephropathogenic strains have been a predominant IBV pathotype only in Australia (Cumming, 1969), with sporadic isolation in other countries. However, during the last decade, nephropathogenic strains have emerged in many countries including Italy, the USA, Belgium, France, China and Japan (Butcher et al., 1989; Wang et al., 1996). In 
some countries of Europe, these strains have become the predominant pathotype of concern (Meulemous et al., 1987). The nephropathogenic IBV strains were able to induce mortality, principally in chicks under the age of ten weeks and differ markedly in virulence, with vairable mortalities of between $5 \%$ and $80 \%$ in experimental infections. This may explain mortality observed in expermint after inoculation of the variant IBV isolates code (4 and 23) as deathes may be resulted from acute renal failure. Changes accompanied with kidney infection with IBV were documented. The serum ions content were affected by the change in electrolyte balance in the kidney and the intake of ions in feeds. The major change in electrolyte balance in the kidney is the increased output of sodium in the urine, which is associated with diuresis (Condron and Marshall, 1985). The ability to reabsorb sodium in infected birds might have damaged, which subsequently led to the low sodium content in the blood. Both the intracellular and renal luminar potassium concentration in IBV-infected birds were lower than those of normal birds (Condron and Marshall, 1991). The higher potassium content in the blood in infected birds might possibly be a consequence of the leakage of potassium from damaged cells and secretory damage. This explain the sever watery feaces observed in groups inoculated with variant IBV isolates as this watery feaces result from polyurea.

In regard of histological changes of the kidney, IBV is the only member of coronaviridae family reported to possess nephropathogenic effects whereas renal epithelial cells containing IBV particles were numerous in the tubular epithelium. The infected epithelial cells in the lower nephrons and ducts showed a marked increase in the amount of rough endoplasmic reticulum (RER), indicating higher susceptibility to the present virus infection. These findings support the view that the production and maturation of coronaviruses are dependent on the structure and function of RER (Klumperman et al., 1994). Virus formation by budding in IBVinfected renal epithelial cells is mostly from membranes of RER (Chen and Itakura, 1996). Physiological studies were recorded in which elevation of plasma uric acid, increasing the urinary water losses beside lowering of urine osmolatity in the IBV-infected chickens. The dilated endoplasmic reticulum in the renal epithelial cells may represnet changes in water and ion transport. The present structural changes in IBV-infected epithelial cells, primarily in the lower nephrons, might indicate that fluid and electrolyte transport were impaired, and thus responsible for the renal failure then death (Chen and Itakura, 1996).

Concerning histopathological lesions in trachea associated with IBV infection in 1day old SPF chicks and examined at 14 days pi, the findings in the mucosa revealed edema, sloughing and degeneration of epithelial cells and activation of globlet cells, which agreed with the findings of Cavanagh and Naqi, (2003). The lamina propria was characterized by massive infiltration by lymphoid inflammatory cells, a result that have been already obtained and reported by Cavanagh and Naqi, (2003), as features which can take place in trachea of birds infected with IBV.

Serum samples taken from SPF chicks 14 days post inoculation with 3 variant IBV isolates code $(4,16$, and 18) and subjected to ELISA test (isolate code 23 could not be examined by ELISA as all chicks died before 14 days of age) showed geometric mean antibody titer lower than 500 which is extremely low for all groups, this may be explained by the short time between infection and detection of antibody response (Avellaneda et al., 1994). But generally the occurrence of low seroconversion in all groups after the inoculation of variant IBV isolates is similar to the finding reported by Gough et al., (1992) who reported that variant IBV strains showed slow seroconversion.

IB was controlled primarily by using attenuated live virus vaccine (e.g., $\mathrm{H}_{120}, \mathrm{Ma}$, commercially available and registered in Egypt) as well as inactivated oil emulsion vaccine, but more than sixty serotypes of IBV have been reported from all over the world (Ignjatovic and Sapats, 2000). So, it is useful for implementation of control measure to determine which IBV serotype(s) have been circulating in region as, protection provided by vaccination with a vaccine of a given serotype, is directed mainly against homologous serotype and less against strains of other serotypes (Davelaar et al., 1984).

In the present study IBV isolates which were characterized as variants, were isolated from flocks had been vaccinated against the IBV using the H120 vaccine which makes the efficacy of such vaccination questionable. By performing in vivo protection study, it was possible to demonstrate the breadth of protection that currently avaliable live IBV H120 vaccine (registered and applied in Egyptian market) can 
provide against challenge with a varity of IBV isolates of several other different genotypes ( code 4,16, 18 and 23) raised in the present work by molecular studies. The vaccine was administered by oculo-nasal route in order to ensure that each chick recived the requred dose of vaccine (Cook et al., 1999). Generally, three main approaches to the assessment of protection have been (1) observation of clinical signs; and removal of trachea at 4 or 5 days after challenge followed by either (2) quantitative assessment of ciliary activity or (3) detection of live challenge virus, usually by inoculation of embryonated eggs (Cavanagh, 2003). The second and the third methods result in similar deductions being made as regards protection (Marquardt et al., 1982). In our study we used observation of clinical signs followed by quantitative assessment of ciliary activity at 5 days after challenge for evaluation of protection as reported by Cook et al., (1999). Clinical signs percentages observed on chicks in groups challenged with isolates code $4,16,18$ and 23 were $100 \%, 50 \%, 100 \%, 100 \%$; respectively. Also, protection percentages based on the quantitative ciliary activity were $8.1 \%$, $55 \%, 10.5 \%$ and $12.6 \%$. Mortality percentage $20 \%$ was observed only in the group challenged by isolate code 23 . This result indicated that H120 could provide only partial protection against challenge with isolate code 16 only, while provide only little protection against the challenge with other 3 isolates. This can be explained by isolate code 16 was related to M41 strain by the S1 sequence ( $97 \%$ match with M41 strain), so H120 (Mass serotype) could provide partial protection against it. Regarding the remanning 3 isolates codes 4,18 and 23 based on the S1 sequence, there were no homology reported between them and the vaccine used so the vaccine provide only little protection against them. This results in agreement with finding that the reports of in vivo cross protection often declines with decreasing S1 sequence homology between vaccinal strain and strains used in challenge (Gelb et al., 2005).

Conclusively, the vaccination programme used in these trials resulted in poor protection of the respiratory tract against challenge with the four new IB serotypes that have been isolated recently in the present work from outbreaks in various governorates in Egypt.

The concept of protectotypes has been suggested to be a valuable one to consider in terms of developing strategies to control IBV infections (Lohr, 1988). The results presented here confirm its value and indicate it to be more relevant in this context than knowing the serotype of a new IB isolate. Rather than spending time determining its serotype, it is probably of more practical relevance in term of control strategies to perform protection studies with the isolate and determine the optimum vaccination programme to protect against it (Cook et al., 1999).

From the above mentioned results, it is clear that H120 live vaccine only is poorly protected against at least four existing new IB serotypes in Egyptian chicken farms, and as a result economic losses will be continous. Using of new serotype(s) of vaccine to face the present status is advisable, in addition to shift of vaccination programmes is highly recommended either as importation of suitable existing serotype(s) or locally prepared from the present existing serotype(s). Inspite, IB still threat for poultry production, where re-emerged vairant(s) still occur.

\section{References}

Abdel-Moneim, A.S.; Madbouly, H.M.; Gelb, J.Jr. and Landman, S. (2002): Isolation and identification of Egypt/Beni-Suef/01 a novel infectious bronchitis-virus genotype. Vet. Med. J. Giza, 50(4): 1065-1078.

Ahmed, H.N. (1954): Incidence and treatment of some infectious viral respiratory diseases of poultry in Egypt. Ph.D.Thesis, Fac. Vet. Med. Cairo Univ., Giza, Egypt.

Ahmed, A.A.S. (1964): Infekiose Bronchitis des Huhnes in Aegypten. Berl. Munch. Tieraztl. Wschr., 77: 481-484.

Ahmed, M.E. (2002): Current status of infectious bronchitis disease in broilers at sharkia governorate. M.V.Sc. Thesis, Fac. Vet. Med. Zagazig. Univ., Egypt.

Amin, Afaf and Mostageer, M. (1977): A preliminary report on an avian infectious bronchitis virus strain associated with nephritis-nephrosis Syndrome in chickens. J. Egypt. Vet. Med. Assoc., 37 (2): 71-79.

Avellaneda, G.E.; Villegas, P.; Jackwood, M.W. and King, D.J. (1994): In vivo evaluation of the pathogenicity of field isolates of infectious bronchitis virus. Avian Dis., 38: 589-597.

Bancroft,J.D. and Stevens,A. (1977): Theory and practices of histologic techniques $2^{\text {nd }}$ Eds. Churchill, Living Stone Edingburgh, London Melborne and New York.

Bastami, M.A.; Amer, M.M. and Hamouda, A.S. (1987): A viral nephritis induced by an isolate related to infectious bronchitis virus. 1. Isolation and identification of the isolate. Assiut. Vet. Med. J., 19 (37): 171-178.

Butcher, G.D.; Winterfield, R.W. and Shapiro, D.P. (1989): An outbreak of nephropathogenic $\mathrm{H}_{13}$ infectious bronchitis in commercial broilers. Avian Dis., 33: 823-826. Cavanagh, D. (2003): Sever acute respiratory syndrome vaccine development: experiences of vaccination against avian infectious bronchitis virus. Avian Pathol., 32:567582.

Cavanagh, D. and Naqi, S.A. (1997): Infectious bronchitis. In B.W. Calnek, H.J. Barnes, C.W. Bearol, L.R. Mc Daugald, and Y.M. Saif (eds). Disease of Poultry $10^{\text {th }}$ ed. Lawa University Press: Ames, IA, pp. 511-526. 
Cavanagh, D. and Naqi, S.A. (2003): Infectious bronchitis in Disease of poultry. B.W Calnek, H.J. Barnes, C.W. Beard, L.R. Mc Dougald and Y.M. Saif (Eds). Disease of Poultry, $11^{\text {th }}$ ed. Ames, IA, Iowa State University Press, pp.101-119

Chen, B.Y. and Itakura, C. (1996): Cytopathology of chick renal epithelial cells experimentally infected with avian infectious bronchitis virus. Avian Pathol., 25: 675690.

Condran, R.J. and Marshall, A.T. (1985): Pathogenesis of infectious bronchitis nephritis. 2. studies of water and electrolyte balance in colostomised chickens. Avian Patho., 14: 509-520.

Condran, R.J. and Marshall, A.T. (1991): Elemental composition of renal proximal tubules and the effect of infection with IBV on electrolyte balance. In: International symposium of infectious bronchitis. II. Kaleta, E.F, ed. pp. 121-126.

Cook, J.K.; Orbell, S.J.; Woods, M.A. and Michael, B. (1999): Breadth of protection of the respiratory tract provided by different live-attenuated infectious bronchitis vaccines against challenge with infectious bronchitis viruses of heterologous serotypes. Avian Pathol., 28:477-485.

Cowen, B.S.; Widemen, R.F.; Braune, M.O. and Owen, R.L. (1987): An infectious bronchitis virus isolated from chickens experiencing a urolethiasis outbreak. I. In vitro characterization studies. Avian Dis., 31: 878-883.

Condran, R.J. and Marshall, A.T. (1985): Pathogenesis of infectious bronchitis nephritis. 2. studies of water and electrolyte balance in colostomised chickens. Avian Pathol., 14: $509-520$

Condran, R.J. and Marshall, A.T. (1991): Elemental composition of renal proximal tubules and the effect of infection with IBV on electrolyte balance. In: International symposium of infectious bronchitis. II. Kaleta, E.F, ed. pp. 121-126.

Cumming, R.B. (1969a): Studies on avian infectious bronchitis virus. 2. Incidence of the virus in broiler and layer flocks, by isolation and serological methods. Aust. Vet. J., 45: 309-311.

Davelaar, F.G.; Kouwenhoven, B. and Burger, A.G. (1984): Occurrence and significance of infectious bronchitis virus variant strains in egg and broiler production in the Netherlands. The Veterinary Quarterly, 6: 114-120.

Dhinakar R. G. and Jones, R.C. (1996): Immunopathogenesis of infection in SPF chicks and commercial broilers of variant infectious bronchitis virus of economic importance. Avian Pathol., 25: 481-501.

Dutta, K.S. (1975): Morphological changes of chicken tracheas and tracheal organ culture infected with avian infectious bronchitis virus studied in scanning Electron microscop. Avian Dis., 19: 429-436.

Eid, A. A.M. (1998): Infectious bronchitis virus in Egypt In proceedigns of III International Symposium on infectious bronchitis and pneumovirus infection in poultry. Rauischholzhausen, German pp. 145-156.

Eissa, Y.M.; Zaher, A. and Nafai, E. (1963): Studies on respiratory diseases: Isolation of infectious bronchitis virus. J. Arab. Vet. Med. Assoc., 23: 381-389.

El-Kady, M.F. (1989): Studies on the epidemiology and means of central of infectious bronchitis disease in chickens in Egypt. Ph. D. Thesis (Poultry Dis). Fac. Vet. Med., Cairo Univ., Giza, Egypt.

Gelb, J., Jr. (1989): Infectious bronchitis. In: purchase et al (Eds). A Laboratory Manual for the Isolation and Identification of Avian Pathogens. $3^{\text {rd }}$.ed.AAAP, pp. 124127.
Gelb, J., Jr.; Weisman, Y.; Ladman, B.S. and Meir, R. (2005): S1 gene characteristics and efficacy of vaccination against infectious bronchits virus field isolates from the United states and Israel (1996 to 2000). Avian Pathol., 34: 194-203.

Gough, R.E.; Randall, C.J.; Dagless, M.; Alexander, D.J.; Cox, W.J. and Pearson, D. (1992): A new strain of infectious bronchitis virus infecting domestic fowl in Great Britain. Vet. Rec., 131: 408-411.

Ignjatovic, J. and Sapats, S. (2000): Avian infectious bronchitis virus. Rev. Sci. Off. Int. Epiz., 19: 493-508.

Klumperman, J.; Locker, J.K.; Meijer, A.; Horzinck, M.C.; Gueze, H.J. and Roittier, P.J. (1994): Coronavirus $\mathrm{M}$ protein accumulate in the Golgi Complex beyond the site of virion budding. J. Virol., 68: 6523-6534.

Lebdah, M.A.; Eid, Amal, A.M. and El-Shafey, A.M. (2004): Infectious bronchitis virus infection among meattype chickens in sharkia province (Egypt). Proc. IV. Int. Symp. On avian Corona-and pneumovirus infections. Rauischholzhausen, Germany, 20-23 June, 2004. pp. 75-86. Lohr, J.E. (1988): Differentiation of IBV strains. In: Proceedings of the $1^{\text {st }}$ Int. Symp.: Infectious Bronchitis. Deutsche Veterinarmedizinische Gesellschaft Gissen, Germany. pp. 199-207.

Madbouly, H.M.; Abdel-Moneim, A.S.; Gelb, J.Jr.; and Landman, B.S. (2002): Molecular characterization of three Egyptian isolates of infectious bronchitis virus. Vet. Med. J. Giza, 50 (4): 1053-1064.

Mahmoud, A.R. (1993): Viruses associated with Coryza infection in chickens. M.V.Sc. Thesis (Poultry Dis). Fac. Vet. Med. Zag. Univ. Egypt.

Marquardt, W.W.; Kadavil, S. K. and Snyder, D.B. (1982): Comparison of ciliary activity and virus recovery from tracheas of chickens and humoral immunity after inoculation with serotype of avian infectious bronchitis. Avian Dis., 26:828-834.

Meulemans, G.; Crlier, M.C.; Gonze, M.; Petit, P. and Vandenbroeck, M. (1987): Incidence, characterisation and prophylaxis of nephropathogenic avian infectious bronchitis viruses. Vet. Rec., 120: 205-206.

Mousa, S.A.; Ibrahim, Nahed, G.; Shehata, M. and Soliman, A. (1988): Epidemiological studies on nephritisnephrosis syndrome. Proc. $3^{\text {rd }}$. Cong. Fac. Vet. Med. Assiut. Univ., November, 20-22, pp. 335-341.

Otsuki, K.; Huggins, M.B. and Cook, J.K. (1990): Comparison of the susceptibility to avian infectious bronchitis virus infection of two inbred lines of white leghorn chickens. Avian Pathol., 19: 467-475.

Reed, L.J. and Muench, H. (1938): A simple method for estimating fifty eprcent endpoint. Am. J. Hyg., 27: 493-496. Sediek, M.M. (2005): Studies on infectious bronchitis in chickens. M.V.Sc, thesis, poultry Dis, Fac. Vet. Med. Alex Univ. Egypt.

Sheble, Atiat.; Sabry, M.Z.; Davelaar, F.G.; Burger, A.R.; Khafagy, A.K.; Moustafa, M.M.; Fawzia, M. and Henna, M. (1986): Present status of infectious bronchitis in Egypt. J. Egypt. Vet. Med. Assoc., 64(4): 393-411.

Smith, H.W.; Cook, J.K. and Parsell, Z.E. (1985): The experimental infection of chickens with mixtures of infectious bronchitis virus and Escherichia coli. J. Gen. Virol., 66: 777-786.

Sultan, H.A.; Tantawi, Lila, A.; Youseif, Aml, I. and Ahmed, A.A.S. (2004): Urolethiasis in white commercial egg laying chickens associated with an ifnectious bronchitis virus. Proc. $6^{\text {th }}$. Sci. Conf. Egypt. Vet. Poult. Assoc., pp: 155-169. 
Villegas, P. and Purchase, G.H. (1990): Preparation of chicken embryo kidney cell cultures (CEKC). In: Laboratory manual for the isolation and identification of avian pathogens. AAAP. Ames, Iowa, USA. pp: 3-4.

Wang, C.H. and Huang, Y.C. (2000): Relationship between serotypes and genotypes based on the hypervariable region of the $\mathrm{S} 1$ gene of infectious bronchitis Virus. Arch Virol., 145: 291-300.

Yu, L.; Wang, Z.; Jiang, Y.; Low, S. and Kwang, J. (2001): Molecular epidemiology of infectious bronchitis virus isolates from China and southeast Asia. Avian Dis., 45: 201-209.

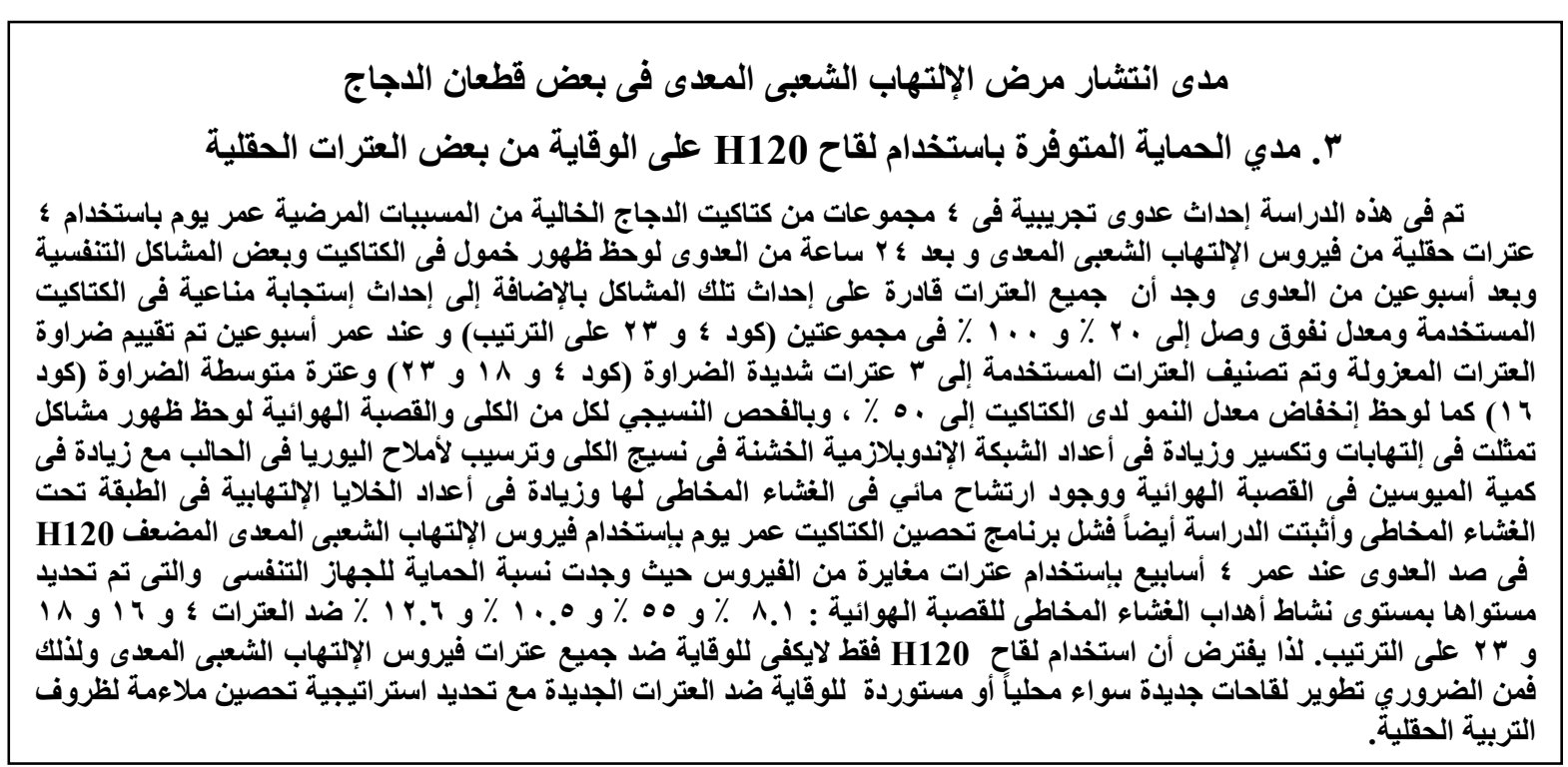

